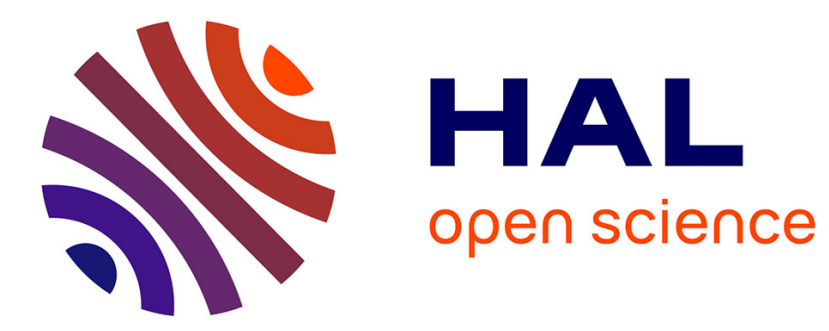

\title{
What does electronic conferencing afford distance education?
}

Sally Barnes

\section{To cite this version:}

Sally Barnes. What does electronic conferencing afford distance education?. Distance Education, 2000, 21(2), 2000, pp.236-247. hal-00190131

\section{HAL Id: hal-00190131 \\ https://telearn.archives-ouvertes.fr/hal-00190131}

Submitted on 23 Nov 2007

HAL is a multi-disciplinary open access archive for the deposit and dissemination of scientific research documents, whether they are published or not. The documents may come from teaching and research institutions in France or abroad, or from public or private research centers.
L'archive ouverte pluridisciplinaire HAL, est destinée au dépôt et à la diffusion de documents scientifiques de niveau recherche, publiés ou non, émanant des établissements d'enseignement et de recherche français ou étrangers, des laboratoires publics ou privés. 


\title{
WHAT DOES ELECTRONIC CONFERENCING AFFORD DISTANCE EDUCATION?
}

\author{
Dr Sally BARNES \\ Centre for Learning, Knowing and Interactive Technology \\ Graduate School of Education \\ University of Bristol \\ 35 Berkeley Square \\ Bristol BS8 1JA UK
}

Email: sally.barnes@bristol.ac.uk

Phone: 011-44-117-968-3088

Fax: 011-44-117-925-1537

Dr Barnes is a Lecturer in the Graduate School of Education. Her teaching and research interests revolve around the integration of ICT into the teaching and learning process, with a particular focus on the integration of electronic and video conferencing techniques. She is the ICT Co-ordinator for her department and works closely with the University Computing Service and others to develop and implement university strategies and policies for use of technology. 


\begin{abstract}
Technology is potentially offering many opportunities to extend and expand distance learning in the higher education sector. Electronic conferencing, in particular, is seen as a technique, which offers opportunities for course delivery and methods of interaction for distant learners. This paper examines the similarities and differences between face-to-face seminars and on-line discussions. Through the concept of affordance it is shown that both benefits and limitations for interaction exist for real and virtual meetings.

It is argued that until we fully understand what it is about face-to-face interactions, which enhance learning, we cannot know what features are required within an electronic conferencing system.
\end{abstract}




\section{WHAT DOES ELECTRONIC CONFERENCING AFFORD DISTANCE EDUCATION?}

In higher education distance learning techniques, which use ICT, in particular electronic conferencing, are seen as ways to enhance the learning process and learning outcomes. The flexibility of asynchronous communication systems provides students with choice about how and when to participate in learning activities.

Research within the area of Information Communication Technology (ICT) often refers to the affordance of a given artefact or tool, referring to the use of ICT as an affordance to learning (cf. Pea 1993; Perkins 1993).

This paper will do three things. It begins with a description and explanation of the concept of affordance as originally coined by James Gibson and what it has come to mean in terms of ICT and its uses in distance education. Secondly, the paper will look at the affordances of electronic conferencing as used within the higher education context. Finally, it will address the research being undertaken to investigate how electronic conferencing systems are being used in higher education and suggests that much more work is needed to examine what effects these techniques have on enhancing the learning process or outcomes and individuals desire for social interaction.

\section{Concept of Affordance}

The concept of affordance was developed by Gibson to explain the connection between perceiving and knowing within his work on visual perception in the 1960s and 1970s. In a break with traditional visual perception research, Gibson suggested that visual perception is more than the mere physical stimulation of cones and rods within the eye but also the ability to apply meaning to what is perceived (Gibson 1966; 1977; 1979). Gibson uses the term 'perceive' as an extension of the psychological sense of an organism's response to physical stimulation. This extension is the ability to attribute meaning to the objects being perceived.

Affordance in Gibson's definition then is both the perception of the physical shapes and constants in the environment and the attribution of meaning to those shapes and constants. So that one can see a chair and also know that it is a shape that can be sat upon.

The affordances of the environment are what it offers the animals, what it provides or furnishes, either for good or ill. The verb to afford is found in the dictionary, but the noun affordance is not. I have made it up. I mean by it something that refers to both the environment and the animal in a way that no existing term does. (Gibson 1979, p. 127) 
Gibson further postulated that the physical shapes we perceive provide us with guidance about how we might act. In this way the shape of an object can guide our behaviour. For example, a well-trodden path in the woods does not imply that this is the only place we can walk. However, it does provide an easy place to walk as well as providing a direction to walk in, if we choose to do so. A shape of the right height and substance can afford sitting regardless of whether it was anticipated it would be used in that way. The affordances are therefore effected by the context with which they exist; they are opportunities for action (Barab, et al 1999) and not a pre-requisite for action. Affordances can be positive or negative. This sense of neutrality is often lost when people use the term "affordance." In one context the affordance could be positive (as in the single path on the woods). However, they could be negative if that path is going in completely the wrong direction.

\section{Affordances, ICT and Distance Education}

The use of the concept of affordances within the ICT world has developed partly from the work of situated learning and in particular the progression between perceiving a thing and attributing a meaning to that thing (Greeno 1994; Ryder and Wilson 1996; Turvey 1992; Wilson and Lawry 2000).

In order to make use of a tool you must first perceive the object as a tool and have the knowledge of how the tool might meet your requirements. Within an ICT environment, the perceptions and affordances through, for example, icons or software, are not always clear or obvious and must in many instances be inferred by the environment or situation in which the learner resides. For example, how to use a computer - the mouse, keyboard, etc; how to infer the meaning of the various icons that are used to delineate applications; how to connect to the Internet and use the computer as a communications tool. More importantly, to know why using such technology may be useful or enhance the learning being undertaken. In other words, in terms of ICT, higher order mental processes are required to infer the meaning from the perceptions we make.

The main issue concerning affordances of ICT and education is how and when ICT is an appropriate medium that enhances the learning process or learning outcomes, in some way. From the advent of the first computers it has been assumed that using ICT will benefit learning. How the use of technology will do this has always been unclear. Initially it was thought that the ability for computers to deliver individualised instruction to learners would allow for enhanced learning outcomes. However, the early drill and practice type programs, while perhaps useful for the learning of multiplication tables and spelling were unable to deliver significantly improved academic results in more substantive areas of learning. Collaborative or group work was not seen to be 
part of this technological revolution, probably due to the limitation of the early technology to encourage collaborative techniques. Recently, work coming out of programmes, such as CSILE (Scardamalia and Bereiter, 1993) suggests that educational techniques which encourage collaborative working among children may encourage students to move into second-order learning environments which enhances both the learning process and learning outcomes. Crowder's work with the National Schools Network suggests individuals adopt different styles of interaction (Crowder 1996; 1998). In the higher education sector research has focussed on the take-up and styles of interaction among students using electronic conferencing systems (Jones, Scanlon \& Blake 2000; Duffy, et al, 1998; Ryder and Wilson 1995; Wilson, et al, in press)

When educators integrate newer computer technology into the curriculum they do so in the belief that somehow the technology will afford learning. Social interaction is a key ingredient in the learning process and anything which affects how it takes place may affect the learning, which occurs (Vygotsky 1978; Wertsch 1985; 1991). It is suggested that combining collaborative techniques with technology will enhance the learning process and learning outcomes dramatically as one of the key affordances of the Internet is for communication, through email, bulletin boards, chats, electronic conferencing (Cicognani 2000; Isenhour, et al 2000; Scardamalia and Bereiter 1993). However, some researchers are questioning whether collaboration through on-line learning is having the desired effect (Roschelle and Pea 1998). Software developers may shape the kinds of social interactions possible between users and communities of users. For example, "attributes of particular email systems influence the ways different communities form, mesh, and fail to mesh" (Gaver 1996,p. 115).

A caveat to ICT is that many of the tools we use in Education are borrowed from other areas and these techniques may not be the most appropriate for enhancing learning. For example, an affordance of the WWW is access to massive amounts of information. However, having access to information does not necessarily imply that people know how to use the information; or that people can evaluate the quality of the information retrieved (Large, Tedd and Hartley 1999). Word processors are another example. They were designed to ease the main editing tasks facing secretaries: moving text from one location to another, changing the presentation of the document, storage and retrieval (Barnes 1993). Word processors were not developed to help people learn how to write or even how to organise their writing (Downes 1998; 1999).

As stated above, learning takes place through social interaction. When we talk about situating ICT within education what we are really suggesting is that the ICT is fully embedded within the learning context - it is not bolted on as an optional extra but is a tool which is used in the same way that we automatically pick up a 
pencil to write or reach for a calculator when doing sums (Lim, 2000). Models of situating ICT in education are based on socio-cultural models of learning with active or proactive learners using tools, which are appropriate for situation-specific tasks (e.g., Bonk and King 1998; Laurillard 1993).

Distance education courses provide materials and support to learners at a distance. These learners organise their study times to suit their own requirements. This self-paced style of learning is seen as affording learning as many of the constraints of time and place are under the individual's control. One key feature of traditional distance learning is the use of face-to-face seminars to augment the individual distance learning component. The iterative process of coming together for brief periods and then working individually has provided a very strong learning environment (Knowles 1984, Richardson, Eysenck and Piper, 1987, Rogers 1986). This is the model the Open University has so successfully developed and utilised in the UK (cf. Jones, et al. 2000; Laurillard 1993; Scanlon and O’Shea 1992)

The introduction of new technologies; in particular, the Internet and conferencing systems are viewed from within higher education institutions as a very positive next step in the development of distance learning programmes (Bonk and King 1998; University of Illinois 1999; Ragan 1998). The main changes are to use the WWW as a medium for providing course materials and to use electronic conferencing as a means of interacting. The face-to-face seminars would then not be so necessary. However, this change from face-to-face interactions to a "virtual" meeting suggests that they are equal in terms of what they give participants. These changes may have profound effects on the learning experiences and learning outcomes of participants.

What we as educators need to be clear about is whether the technology available is suitable for educational purposes or whether we are adapting our methods and requirements to fit the available technology at the expense of good educational practice.

\section{Affordances of Electronic Conferencing}

Electronic conferencing systems used the technology of the original Email systems and changed the purpose and conduct of use considerably.

...new designs change the environment for interaction, they show old behaviors in a new light and illustrate how new behaviors emerge. (Gaver 1996,p. 115)

An original affordance of Email was as a system for one-to-one communication. The advent of mailing lists, in particular, extended email to a one-to-many system. Within organisations, Email, provides yet another method for distributing information among members. In the world of the paperless office Email was going to replace memos, telephone messages, short letters and even agendas and minutes for meetings. It is seen as a way 
that a group of individuals can communicate fast and effectively without the need for secretaries. However, in most organisations, email and paper are used interchangeably for many purposes and it is not always clear why one method of communication is used over another.

Email also has the affordance of being a tool for social interaction. As such it is very important that systems of use be explicitly created and understood within a community of users. When the etiquette of when to reply or copy messages are clear email users have more confidence in relying on the system as a means of communication. If email systems are incompatible or difficult to use the affordances of social interaction may be lost as it is frustrating to make the system work as you expect it to. Mismatches in expectations can afford a sense of social isolation and paranoia about being left out of the information loop when an email message is sent to only part of a group (or to a whole group by mistake!). Receiving an email from a friend on the other side of the world affords "staying in touch". The instant communication Email affords brings us messages we wish to receive as well as the "junk" mail we may wish we didn't.

Communities of email users within organisations often develop their own methods of practice (Gaver 1996). This might include whether emails are acknowledged or replied to; or when messages are copied or forwarded to other members. Over time, a community develops standards of practice. These may be explicit or implicit, but most members will become aware of the etiquette involved in using email within their own community. Most of us, however, send emails to individuals outside of our normal email community (i.e., other universities, business colleagues, Ecommerce). We need to both perceive and understand the use of Email within other email communities before we react as we might within our own email community.

Whereas Email developed as a one-to-one, or one-to -many, open communication system, the original concept behind electronic conferencing systems was to afford one-to-many communication within a closed group. Only individuals registered on a conference have access to the conference to read or post messages. Conferencing systems were originally developed as a business tool for members in different locations to meet virtually. Virtual meetings would save businesses time and money yet still allow for interaction among a group of people. Therefore, an affordance of meeting virtually was that the need for face-to-face meetings might diminish or that their purpose would change.

Electronic conferencing is a closed community, usually with a specific purpose in mind. Therefore members of a conference may develop an agreed etiquette for posting messages and information. This suggests 
that a conference may have an opportunity to achieve group cohesion similar to that found in groups, which meet face-to-face.

In higher education, and in particular distance education, electronic conferencing has been adopted as one of the suite of techniques available to the learner (cf. Bonk and King 1998). Conferences may act as the delivery mechanism of learning materials (lecture presentations, readings, assignments, etc). However, a key affordance of electronic conferencing is the ability for on-line discussions within a closed group. Learners can interact about a topic, or reading, work collaboratively, post assignments, whatever. The asynchronicity of the system allows for instant communication as well as the opportunity to be reflective and considered when posting messages.

\section{Face-to-Face Interactions versus Electronic Conferencing}

A common feature of face-to-face seminars is the way different individuals interact within the group. In face-to-face learning groups, some individuals talk and others are silent. There is much more than verbal exchanges taking place within the group (McNeil 1992). Non-verbal signals are being sent all the time among participants (Crowder 1996) and one can actively participate without making a verbal contribution. In an electronic conference, however, the only visible sign of participation is the written word. The main distinction between face-to-face and virtual meetings is the shift to use text rather than voice to play with ideas among a group. A feature of many face-to-face seminars is the in free-flowing spontaneity of ideas and the general enthusiasm generated within a group. After such experiences it is often possible for people to generate written text both summarising and extending these ideas drawing on their memories, images, sounds, notes and other tools for stimulating ideas. But to do so all in text using electronic conferencing may require real determination to overcome the sense of social isolation.

People who are actively reading and thinking but not posting messages, in a conference, are often viewed as not participating. The research literature describes these individuals as "lurkers" who read everything posted but do not post messages (Selinger 1998; Pearson 1999a; 1999b). What is interesting about lurkers is that they are usually not a problem within face-to-face situations (and it may be different people who "lurk" in different situations). However, within electronic conference environments lurkers, at times, are viewed as a threat to the group. Issues about why some individuals don't post messages, or what they might be thinking can lead to groups fading. So to shift from face-to-face to electronic conferencing techniques requires finding ways for all learners to participate in ways they feel comfortable with. 
The iterative process of seminar participation is characterised by a coming together of a group for faceto-face interaction followed by a period of non-meeting when more reflective types of activities can occur. Though clearly we may have conversations with fellow learners between seminars, at the actual seminar the very act of coming together as a group may allow for a top-up of ideas, enthusiasm, and motivation. The asynchronicity of an electronic conference is characterised by a more continuous drip-feed of offerings by individuals which may make it difficult to create a situation of group versus individual self-paced work.

It is interesting to consider what the optimal number of participants can be in different learning situations. Face-to-face seminars seem to work well with between 4-15 people. Less than 4 and people feel under pressure, more than 15 and people can't participate adequately. With electronic conferences there is a real dilemma. Using the Internet as the chief mode of communication suggests that many more people can access web-based course materials as only the speed and capacity of the network restrict access to the WWW. However, in terms of using conferencing for on-line discussions, communicating through text is more complicated than voice and most viable conferences have between 4 and 8 people with 6 being the optimum number (Barnes 1999; Pearson 1999a).

\section{Links between Email and Electronic Conferencing}

One difficulty experienced by many people using Email and electronic conferencing is that the similarity between the systems actually makes it difficult to shift between them. Many Email systems have user friendly interfaces similar, in style and icons, to other applications. Electronic conferencing systems, which have many of the same features as Email systems often, look different and are perceived to be different. The affordances of how to communicate may be lost through this lack of similarity in features to other packages being used.

The major difficulties in using electronic conferencing effectively are more profound. People are generally familiar with using Email as a form of interaction but are less familiar with communicating within the closed community of a conference. It is one thing to email a colleague about a range of work-related issues and another to participate in a group about the assignment you are working on for a course.

To use electronic conferencing systems requires a shift in thinking for many users, away from passing bits of information or asking questions to engaging in a debate or going out on a limb grappling with new ideas. This shift involves moving from interacting verbally to developing techniques where text-based interchanges are as spontaneous as face-to-face interactions. 
The affordances of face-to-face meetings and electronic conferencing for distance education form a balance, with a negative affordance of one being the positive affordance of the other. A positive affordance of meeting face-to-face is the opportunity for verbal exchanges augmented by all the non-verbal signals we send each other; this could be seen as negative affordance of virtual meetings, where no verbal and non-verbal cues are present. A positive affordance of virtual meetings is their asynchrocity, which allows members to access and make offerings at times most suited to them. These offerings are text-based and allow for reflective thought. These could be seen as negative affordances of face-to-face meetings when free-flowing spontaneity can occur.

The learning benefits of face-to-face seminars or discussions are well assumed. However, we have never really examined what features of face-to-face interactions are critical to enhance learning. Is it the actual verbal exchanges; is it the non-verbal gestures and facial expressions, which encourage us? Is it the spontaneity of listening and having ideas spark off one another? Does the very act of coming together as a group allow for social relationships to develop which then enhance the learning?

Conversely, what inhibits learning in face-to-meetings? Does the spontaneity discourage reflective thought afterwards? Do the non-verbal cues inhibit us?

Similar questions need to be addressed in research on the use of electronic conferencing for distance education. For example, what is the effect of participating in discussion using text on the learning process? We do not yet know what forms of interaction people need, want or expect in order to support their learning.

Electronic conferencing has much to offer learners, at a distance, but we do not yet know whether their learning process or outcomes are different (better or worse) than learners in face-to-face situations or learners using a mixed-model approach.

These are important research issues which, when addressed, will help us develop technological systems which adequately and appropriately support learning.

\section{Summary}

Three key areas were covered this paper. First, that there are affordances to face-to-face styles of learning and affordances to electronic conferencing for distance education. The affordances are both positive and negative. The affordances of face-to-face interactions are what we have grown up with and are probably most comfortable with. There is an assumption that whatever occurs in face-to-face interactions somehow 
benefits learning. The affordances for learning with electronic conferencing are less well documented but assumed to be there through the asynchronicity and self-paced nature of the interaction.

The second idea presented is that before we move to more technologically based forms of learning we need to fully understand what the ingredients are of face-to-face interactions and electronic conferencing that enhance the learning process or learning outcomes.

Finally, the concept of affordances, as originally developed by James Gibson, provides a very useful way of considering the benefits and limitations in the perceiving and knowing of the technological tools available to us for learning. 


\section{References}

Barab, S.A., Chekes-Julkowski, M., Swenson, R., Garrett, S., Shaw, R.E., and Young, M. (1999) Principles of self-organization: Learning as participation in autocatakinetic systems. The Journal of the Learning Sciences, 8(3\&4), pp. 349-390.

Barnes, S.B. 1993 Individual differences in learning to use a word processing system. Unpublished doctoral dissertation, University of Bristol, Bristol, UK.

Barnes, S.B. 1999 Electronic Conferencing to Support post-graduate students working at a distance. Interact, vol 19, October, pp.18-19.

Bonk, C.J., Cummings, J.A., Hara, N., Fischler, R.B. and Less, S.M. A Ten level web integration continuum for higher education: New resources, partners, courses, and markets http://php.indiana.edu/ cjbonk/paper/edmdia99.html (Accessed December 1999)

Bonk, C.J. and King, K. S. (Eds.) 1998 Electronic collaborators: learner-centred technologies for literacy, apprenticeship and discourse, Lawrence Earlbaum Associates, Hillsdale, N.J.

Cicognani, A. (2000) Concept mapping as a collaborative tool for enhanced on-line learning. Educational Technology \& Society, 3(3) pp 150-158

Crowder, E.M. (1996) Gestures at work in sense-making science talk. The Journal of the Learning Sciences, 5(3), pp. 173-208.

Crowder, E.M.(1998) Can live on-line forums support learning conversations? Paper presented at American Education Research Association Annual meeting, 1998.

Downes, T. I. 1998 Children's use of computers in their homes. PhD dissertation submitted to the University of Western Sydney Macarthur, Sydney, Australia.

Downes, T. I. 1999 Discourses about children's uses of computers at home and at school. Paper presented at the Centre for Learning, Knowing and Interactive Technology, Bristol University June.

Duffy, T.M., Dueber, B. and Hawley, C.L. (1998) Critical thinking in a distributed environment: A pedagogical base for the design of conferencing systems. In Bonk, C.J. and King, K. S. (Eds.) 1998 Electronic collaborators: learner-centred technologies for literacy, apprenticeship and discourse, Lawrence Earlbaum Associates, Hillsdale, N.J. pp. 51-78.

Gaver, W. W. 1996 Situating action II: Affordances for interaction: The social is material for design. Ecological Psychology, vol. 8, no. 2, pp.111-129.

Gibson, J.J. 1966 The Senses considered as perceptual systems, Houghton Mifflin, Boston.

Gibson, J.J. 1977 The Theory of affordances. In Shaw, R. And Bransford, J. (Eds.), Perceiving, acting, and knowing: Toward an ecological psychology, Lawrence Erlbaum Associates, Hillsdale, N.J.

Gibson, J.J. 1979 The Ecological approach to visual perception, Houghton-Mifflin, Boston.

Greeno, J. 1994 Gibson's Affordances. Psychological Review, vol. 101 no. 2, pp. 336-342.

Isenhour, P.L., Carroll, J.M., Neale, D.C., Rosson, M.B. and Dunlap, R. (2000) The Virtual school: an Integrated collaborative environment for the classroom. Educational Technology \& Society, 3(3) pp 7486.

Jones, A., Scanlon, E. and Blake, C. (2000) Conferencing in communities of learners: Examples from social history and science communication. Educational Technology \& Society, 3(3) pp 215-226.

Knowles, M.S. 1984 The adult learner: A neglected species ( $3^{\text {rd }}$ edition), Gulf, Houston.

Large, A., Tedd, L.A. and Hartley, R.J. 1999 Information seeking in the on-line age, Bowker Saur, London.

Laurillard, D. 1993 Rethinking university teaching: A framework for the effective use of educational technology, Routledge, London

Lim, C.P. 2000 Situating information and communication technologies (ICT) in the economics course. Unpublished doctoral dissertation, University of Bristol, Bristol UK. 
McNeil, D. (1992) So you do think gestures are non-verbal! Reply to Feyereisen (1987). Psychological Review 94 pp. 499-504.

Pea, R.D. 1993 Practices of distributed intelligence and design for education. In Salomon, G. (Ed.), Distributed cognitions: Psychological and educational considerations, Cambridge University Press, Cambridge.

Pearson, J. 1999a Electronic conferencing in initial teacher education: is a virtual faculty of education possible? Computers and Education, vol. 32, pp. 221-238.

Pearson, J. 1999b Lurking anonymity and participation in computer conferencing: data from a case study on an initial teacher education course, paper presented CommNEd99, Hameenlina, Finland, June.

Perkins, D. N. 1993 Person-plus: A distributed view of thinking and learning. In Salomon, G. (Ed.), Distributed cognitions: Psychological and educational considerations, Cambridge University Press, Cambridge.

Ragan, L.C. 1998 Good teaching is good teaching: An Emerging set of guiding principles and practices for the design and development of distance education. DEOSNEWS, 8 (12) http://www.ed.psu.edu/ACSDE/ (accessed January 2000).

Richardson, J.T.E., Eysenck, M.W. \& Piper, D.W. 1987, Student learning: Research in education and cognitive psychology, Open University Press, Milton Keynes.

Rogers, A. 1986, Teaching adults, Open University Press, Milton Keynes.

Roschelle, J. and Pea, R. (1998) Educational Researcher, 27(3), pp. 22-25.

Ryder, M. and Wilson, B. (1995) From local to virtual learning environments: making the connection. Paper presented at the annual meeting of the American Educational Research Association 1995 (available at: http://www.cudenver.edu/ mryder/aera95.html)

Ryder, M. and Wilson, B. (1996) Affordances and constraints of the internet for learning and instruction. Paper presented to a joint session of the Association for Educational Communications Technology, Indianapolis, 1996 (available at: http://www.cudenver.edu/ mryder/aect_96.html)

Scanlon, E. and O'Shea, T. (Eds.), (1992) New directions in educational technology. Springer-Verlag, Berlin

Scardamalia, M. and Bereiter, C. (1993) Computer support for knowledge-building communities.. The Journal of the Learning Sciences, 3(3), pp. 265-283.

Selinger, M. 1998 Forming a critical community through telematics. Computers in Education, vol. 30, no.1/2, pp. 23-30.

Turvey, M. T. (1992) Affordances and prospective control: An outline of an ontology. Ecological Psychology, 4, pp. 173-187.

University of Illinois Faculty Seminar 1999 Teaching at an Internet Distance: The Pedagogy of online teaching and learning. Report to the Vice-President's Office, University of Illinois, http://www.vpaa.uillinois.edu/tid/report (accessed December 1999).

Vygotsky, L.S. 1978 Mind in society: the development of higher psychological processes, MIT Press, Cambridge.

Wertsch, J.V. 1985 Vygotsky and the social formation of mind, Harvard University Press, Cambridge.

Wertsch, J.V. 1991 Voices of the mind: a sociocultural approach to mediated action, Simon and Schuster, New York.

Wilson, B. and Lowry (2000) Constructivist learning on the web. In Burge, L. (Ed), Learning technologies: reflective and strategic thinking. Jossey-Bass, San Francisco (available at: http://ceo.cudenver.edu/ brent_wilson/WebLearning.html)

Wilson, B., Sherry, L., Dobrovolny, J., Batty, M and Ryder, M. (in press) Adoption of learning technologies in schools and universities. In Adelsberger, H.H., Collis, B. and Pawlowski, J.M. (Eds), Handbook on information technologies for education and training. Springer-Verlag, Berlin. 